\title{
O VALOR DA MARCA: CONCEITOS, ABORDAGENS E ESTUDOS NO BRASIL
}

\author{
Marta Olivia Rovedder de Oliveira \\ martaoliveira@unipampa.edu.br \\ Universidade Federal do Pampa - RS/Brasil \\ Fernando Bins Luce \\ fbluce@ea.ufrgs.br \\ Universidade Federal do Rio Grande do Sul - RS/Brasil
}

Recebido em 13/08/2008

Aprovado em 12/04/2011

Disponibilizado em 01/08/2011

Avaliado pelo sistema double blind review

Revista Eletrônica de Administração

Editor: Luís Felipe Nascimento

ISSN 1413-2311 (versão on-line)

Editada pela Escola de Administração da Universidade Federal do Rio Grande do Sul.

Periodicidade: Quadrimestral

Sistema requerido: Adobe Acrobat Reader.

\section{INTRODUÇÃO}

A marca é um fator crítico de sucesso para as organizações, sejam elas comerciais, industriais, instituições de caridade, partidos políticos etc. Estrategicamente, marcas fortes representam um componente da vantagem competitiva e fonte de futuros ganhos da empresa (BALDAUF; CRAVENS; BINDER, 2003). Para o cliente, as marcas frequentemente oferecem os principais pontos de diferenciação entre as ofertas competidoras e, assim, podem ser consideradas decisivas para o sucesso das companhias (WOOD, 2000).

O branding surgiu como uma das prioridades das companhias na última década devido à crescente compreensão de que as marcas são um dos ativos intangíveis mais valiosos que as empresas possuem (KELLER; LEHMANN, 2006). Apesar de o mundo corporativo reconhecer o branding como uma importante atividade de marketing, os executivos de marketing ainda são desafiados a substituir o valor do branding em claros termos financeiros (MADDEN; FEHLE; FOURNIER, 2006). Frequentemente, outros membros da companhia discutem que os gestores de marketing tomam decisões baseadas na intuição e dados de relevância questionável (YEUNG; RAMASAMY, 2007). 
Torna-se cada vez mais claro para as empresas que "o branding e a construção de marca devem estar focadas no desenvolvimento de valor da marca” (GUZMÁN, 2004, p. 2). Os financistas veem que as marcas são ativos financeiros e estratégicos, haja vista seu poder de influenciar consumidores, parceiros, colaboradores e de interferir nos canais de vendas, distribuição e nas condições e termos de fornecimento. Além disso, a marca mobiliza interesse dos investidores e pode transformar o desempenho da organização e o seu resultado financeiro.

Se o marketing conseguisse quantificar suas ações e resultados, tais como o valor da marca - segundo a perspectiva financeira ou da firma-, poderia recuperar sua credibilidade abalada com a sua prolongada inabilidade em contabilizar seu impacto nos lucros (YEUNG; RAMASAMY, 2007). Reportar as métricas do valor da marca também permitiria aos profissionais de marketing se comunicar com públicos de quem tipicamente mantêm distância, utilizando a linguagem que os acionistas e diretores apreciam e entendem (SRIVASTAVA; SHERVANI; FAHEY; 1998; MADDEN; FEHLE; FOURNIER, 2006). Ao mesmo tempo, existe um crescente reconhecimento de que as marcas são recursos capazes de melhorar o valor ao acionista, pois possuem valor econômico (AAKER, 1996a; MONTANGES; RIEL, 2003). O valor da marca, portanto, é considerado um importante construto a ser estudado, pois é associado a benefícios-chave tanto para consumidores quanto para empresas (SHANKAR, AZAR; FULLER, 2007).

De acordo com Raggio e Leone (2007), em anos recentes, mais especificamente durante os últimos 15 anos, o valor da marca tem sido foco da pesquisa acadêmica e da prática administrativa (AAKER, 1996b; KELLER, 1993; SHANKAR; AZAR; FULLER, 2007). Ressalta-se que esse tema encontra-se entre as prioridades de pesquisa do MSI de 2006-2008, nos tópicos relativos a métricas, integrando métricas de desempenho financeiro e não financeiro, bem como no tópico que relaciona valor da marca e valor do cliente ao desempenho da firma. Além disso, figura no tópico que trata especificamente de brand equity. Já nas prioridades de 2010-2012, é destacada a gestão de marcas em um ambiente de mudanças.

Entretanto, segundo Martins (2007), CEO da GlobalBrands, embora as pesquisas sobre o valor da marca sejam muito comuns na Europa e Estados Unidos, ainda são incipientes no Brasil. Dessa forma, o presente estudo visa verificar os estudos relativos ao valor da marca realizados no Brasil. Para tanto, primeiramente revisa os conceitos e abordagens existentes. Destaca-se que, apesar do termo valor da marca ser a tradução para o português dos termos ingleses "brand equity" e "brand value", existem autores que os tratam 
O valor da marca: conceitos, abordagens e estudos no Brasil

diferentemente (ex.: FELDWICK, 1996; RAGGIO; LEONE, 2007), e outros que não fazem distinção entre os termos (ex.: SIMON; SULLIVAN, 1993; KELLER; LEHMANN, 2006; SHANKAR; AZAR; FULLER, 2007).

A avaliação da marca é considerada relevante tanto pelos práticos quanto pelos acadêmicos. O Journal of Marketing, por exemplo, um dos principais periódicos internacionais da área de marketing, apresentou uma chamada de propostas e papers ("Marketing strategy meets Wall Street”), com um tópico intitulado "Entendendo a avaliação da marca”. Na edição de Novembro de 2009 (volume 73), foram publicados os artigos de Krasnikov et al. (2009), Mizik e Jacobson (2009), Thorsten et al. (2009), todos relativos ao valor da marca ou ao impacto financeiro das marcas. Além disso, nessa mesma edição foi publicado um artigo sobre valor da marca baseado nos consumidores de Rego et al. (2009).

Por fim, esta pesquisa tem como principal objetivo realizar um levantamento dentre as principais publicações brasileiras sobre os estudos realizados sobre o valor da marca. Tal levantamento busca verificar o quanto a academia brasileira já se dedicou a esse tema, mas principalmente objetiva fomentar o desenvolvimento de futuros trabalhos sobre esse objeto.

\section{REVISÃO DA LITERATURA}

Esta seção é composta por uma revisão dos conceitos sobre valor da marca e de trabalhos relativos à mensuração do valor da marca.

\subsection{Valor da Marca}

Uma marca pode ser definida como um nome, termo, sinal ou símbolo ou combinação desses que objetiva identificar mercadorias e serviços de um vendedor ou grupo de vendedores e diferenciá-los dos competidores (AMA, 1960). Essa definição foi criticada por ser muito focada no produto. Dessa forma, a American Marketing Association realizou uma pequena alteração na conceituação de marca para: um nome, termo, design, símbolo ou qualquer outro aspecto que identifica um produto ou serviço de uma empresa como distinto daqueles das outras (AMA, 2010).

A principal mudança da definição original para a atualmente recomendada pela AMA, segundo Wood (2000), é a adição das palavras “ou qualquer outro aspecto”, pois isto permite a inclusão dos intangíveis, tais como imagem, como ponto de diferenciação. O valor especial dessa definição está no foco fundamental do propósito da marca, que é a diferenciação (WOOD, 2000). 
Já para Kapferer (2004a, p. 14), “a marca é um sistema vivo composto de três elementos: um multissinal (nome, identidade gráfica, símbolo), associado a um (ou mais) produto(s)/serviço(s), ao(s) qual(is) é associada uma promessa de qualidade, segurança e pertinência a um universo".

Dessa forma, compreende-se que a marca, originalmente utilizada como caracterizadora de propriedade e de origem de um produto, avançou em conceito e significado. Considerada inicialmente como um patrimônio da empresa por ser uma propriedade definida pela legislação comercial como exclusiva e vitalícia (KOTLER, 1994); seu valor é atualmente aceito como um ativo baseado em mercado (RUST; LEMON; ZEITHAML, 2004a; SRIVASTAVA, SHERVANI, FAHEY, 1998; FISCHER, 2007), por permitir a diferenciação em relação a seus concorrentes. Nessa corrente de pensamento, Shankar, Azar e Fuller (2007) acreditam que a visão da marca necessitava ser mudada de um símbolo de um produto para um recurso quantificável. Assim, surgiu o conceito de valor da marca (brand equity), o qual rapidamente emergiu como o assunto central no entendimento do valor de marketing (RUST, AMBLER, CARPENTER, KUMAR, SRIVASTAVA, 2004b; SHANKAR; AZAR; FULLER, 2007).

De acordo com Vargas Neto (2003), o construto brand equity realmente ganhou notoriedade quando o MSI - Marketing Science Institute realizou um congresso específico sobre brand equity, em 1988. Desde então, tem se tornado um conceito cada vez mais respeitado. Não se sabe ao certo quem cunhou o termo brand equity, mas esse já aparecia em alguns trabalhos na primeira metade da década de 80 (FELDWICK, 1996). A partir dessa década, ocorreu um grande crescimento nas fusões e aquisições, onde as marcas com as melhores posições ofereciam vantagens nas negociações para os grupos detentores.

De acordo com Côrte-Real (2006, p.3), o termo "valor da marca, que na linguagem anglo-saxônica é designado por brand equity”, assim como os conceitos de brand e added value, têm se proliferado em múltiplos significados (WOOD, 2000), sendo vistos "através de uma variedade de perspectivas" (KELLER, 1993, p.1). Essas diferentes abordagens definidoras do construto proveem de distintas filosofias e perspectivas (WOOD, 2000), sendo umas meramente qualitativas, outras meramente financeiras, outras segundo a perspectiva de valor apenas para a organização, outras na perspectiva do consumidor (CÔRTE-REAL, 2006). Algumas dessas definições são apresentadas no Quadro 1, segundo uma pesquisa realizada por Keller (1998): 


\section{Definiç̃es de "Valor de Marca"}

Conjunto de associações e comportamentos por parte dos consumidores de uma marca, distribuidores e empresa mantenedora da marca, que permite à marca obter maior volume de vendas ou maiores margens de mercado do que seria possível sem o nome da marca, assim como uma mais forte e sustentável vantagem diferencial sobre os concorrentes.

Adição de valor para a empresa, para o negócio ou consumidor, com a qual uma dada marca complementa um produto.

Conjunto de ativos e passivos ligados a uma marca, ao seu nome e símbolo, que se adicionam ou se subtraem ao valor proporcionado por um produto ou serviço, em benefício da empresa e de seus clientes.

Impacto lucrativo sobre as vendas advindas do resultado dos esforços passados de Marketing em marca se comparado com o desempenho de uma nova marca.

Brand equity é a resultante da força da marca mais o valor da marca. A força da marca é o conjunto de associações e comportamentos dos consumidores, distribuidores e empresa controladora da marca que permitem à marca desfrutar vantagens competitivas diferenciais e sustentáveis. O valor da marca é o resultado financeiro resultante da habilidade de gestão para potencializar a força da marca através de ações táticas e estratégicas em favor de lucros correntes e futuros e da diminuição dos riscos.

Valor financeiro mensurável de transações acumulada sobre o produto ou serviço decorrente de programas e atividades bem-sucedidas.

"Valor de marca" decorre da boa vontade de alguém continuar comprando sua marca ou não. Desta forma, a mensuração do "valor de marca" está fortemente relacionada à lealdade e à medida de conversão de diferentes consumidores em usuários da marca.

Valor suplementar que se situa para além dos seus ativos físicos. Este valor provém da posição que a empresa detém no mercado em relação à que teria na ausência da marca.

Quadro 1 - Definições de "valor da marca"

Fonte: KELLER (1998, p.43) e STRINGHETTI (2001).
Autoria

Marketing Science Institute (1980)

\section{Peter Farquhar,}

Claremont

GraduateSchool

(1989)

David Aaker,

University of

California at

Berkeley (1991)

John Brodsky, NPD Group (1991)

Raj Srivastava, University of Texas e Allan Shocker, University of Minnesota (1991)

J. Walker Smith, Y.C.Schulman (1991)

Market Facts

Dimitriadis (1994)

Essa multiplicidade de conceituações de valor da marca também se deve à complexidade do termo "valor". "O conceito de valor encontra suas origens em várias disciplinas, incluindo psicologia, psicologia social, economia, marketing e administração" (WOODRUFF, GARDIAL, 1996, p. 54), fazendo com que existam várias definições sobre o termo "valor". Além disso, existem diferentes perspectivas sobre o valor, pois o que constitui o valor é algo extremamente pessoal e idiossincrático (ZEITHAML, 1998). Como decorrência disto, o termo "valor da marca" tem recebido várias definições, oriundas tanto de profissionais da área financeira ou de contabilidade quanto de marketing. Dentre essas definições, basicamente pode-se agrupar os conceitos relativos ao valor da marca em dois grupos: com base na perspectiva da firma e segundo o prisma do consumidor.

Segundo Wood (2000), os contabilistas tendem a definir valor da marca diferentemente dos profissionais de marketing, embora ambos utilizem o mesmo termo (brand equity). Os contabilistas apresentam uma definição orientada exclusivamente para a empresa, percebendo as marcas como um ativo intangível, passível de ser capitalizado, 
apresentando assim relevância na mensuração do patrimônio das entidades quando ocorre um processo de compra de marca. Nesse contexto, a marca representa um bem, que pode ser adquirido ou vendido por um determinado valor. Segundo Feldwick (1996), o valor da marca é um ativo em separável quando ela é vendida ou incluída no Balanço Patrimonial. O brand equity, segundo a perspectiva da empresa, pode ser definido como o valor presente líquido dos fluxos de caixa (DCF) incrementais atribuídos para um nome de marca e para uma empresa que possui a marca em seu(s) produto(s) e serviço(s) comparado a produtos idênticos com nenhum nome de marca ou esforços de construção de marca (KELLER, 1993, 1998; KELLER; LEHMANN, 2006; RUST et al., 2004b; SHANKAR; AZAR; FULLER, 2007; FISCHER, 2007).

Vargas Neto (2003) destaca que a mensuração de brand equity orientada para a empresa (WOOD, 2000) ou contabilidade (MORGAN, 2000) tende a definir valores em moeda corrente para as marcas. "Por exemplo, a Interbrand estimou o valor da marca da Home Depot em US\$ 84 bilhões em 1999” (TYBOUT; CARPENTER, 2000 apud RUST et al., 2004b). Além disso, Vargas Neto (2003) aponta algumas características ou funções da mensuração: definir um preço quando a marca é vendida (FELDWICK, 1996); ser um ativo a ser gerido (MORGAN, 2000); incluir a marca como um ativo intangível no balanço da empresa (FELDIWICK, 1996); possibilitar o valor incremental no fluxo de caixa resultante da venda da oferta com a marca em relação à venda sem marca (MORGAN, 2000; FISCHER, 2007); aumentar a participação de mercado (MORGAN, 2000).

Já os profissionais de marketing tendem a definir o valor da marca segundo a perspectiva do consumidor ou com uma visão dupla - da empresa e do consumidor -, conforme se pode perceber na definição de Keller e Machado (2006), onde o valor patrimonial de uma marca ou brand equity representa as ferramentas utilizadas para o posicionamento, a comunicação e a venda da marca, de forma que entregue valor aos clientes e proporcione retorno financeiro para as empresas.

Para a AMA (2008), "brand equity significa o valor da marca. Da perspectiva do consumidor, brand equity é baseado nas atitudes do consumidor sobre atributos positivos da marca e consequências favoráveis do uso da marca". A equidade da marca sob a óptica do consumidor é, para Aaker (1996b), um conjunto de recursos e deficiências, inerentes a uma marca, que agregam ou subtraem valor a um produto. Dessa forma, "do ponto de vista do cliente, o brand equity é parte da atração - ou repulsão - a um produto de uma determinada empresa [...]. O valor da marca e sua equidade são derivados das palavras e ações dos consumidores" (KELLER; LEHMANN, 2006, p.14). Uma marca com brand equity positivo 
O valor da marca: conceitos, abordagens e estudos no Brasil

obtém mais respostas favoráveis dos clientes do que uma versão de produto ou serviço sem nome (KELLER e MACHADO, 2006).

Para Aaker (1996a), o valor da marca consiste de cinco dimensões relativas à percepção do consumidor: lealdade à marca, consciência do nome, qualidade percebida, associações da marca e outros ativos da empresa, conforme aponta a Figura 1. Ressalta-se que, para esse autor, o valor da marca impacta tanto o valor para o cliente quanto o valor da empresa.

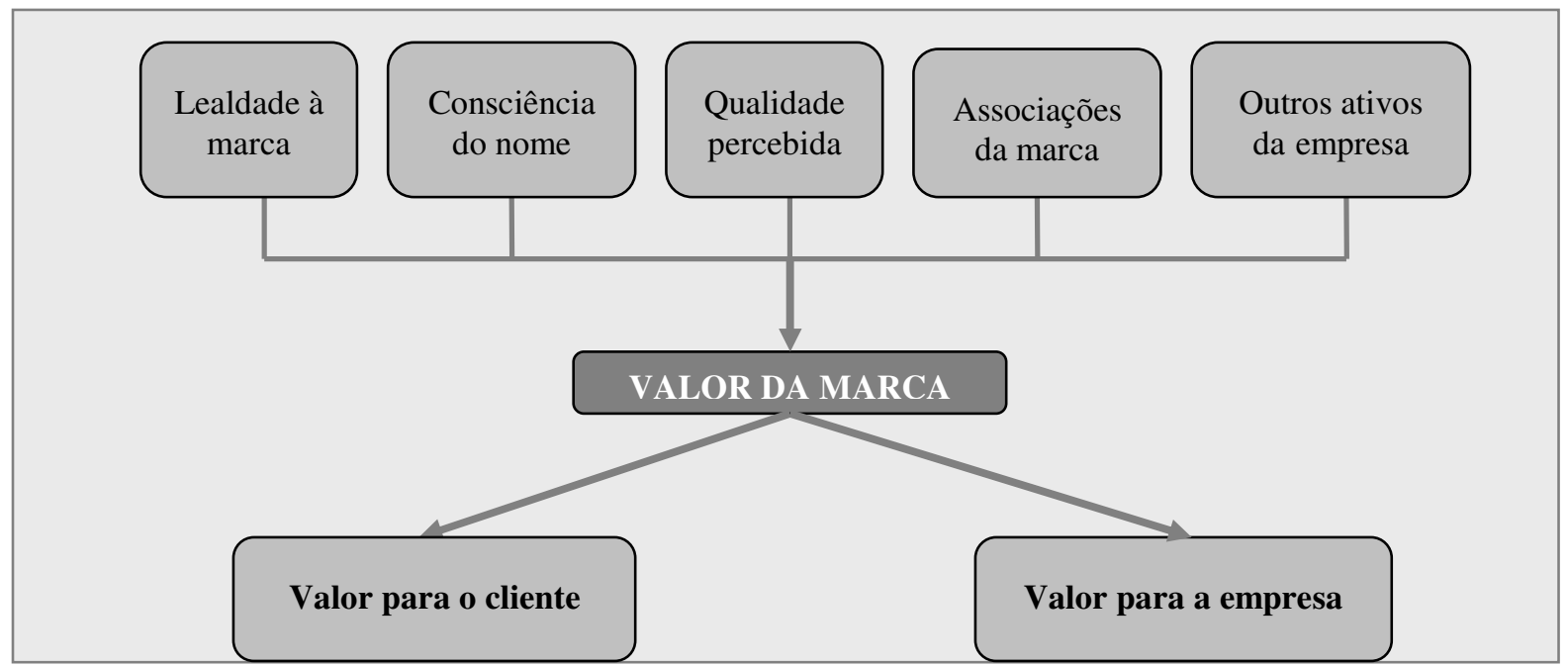

Figura 1 - Modelo de Aaker de "valor da marca"

Fonte: Aaker (1996a)

Yoo et al. (2000) propõem uma extensão do modelo conceitual de Aaker, conforme ilustra a Figura 2. Esses autores acreditam que as atividades de marketing realizadas pela empresa possuem grande potencial para afetar as dimensões do valor de marca, e este potencial representa o efeito acumulado dos investimentos de marketing sobre uma marca.

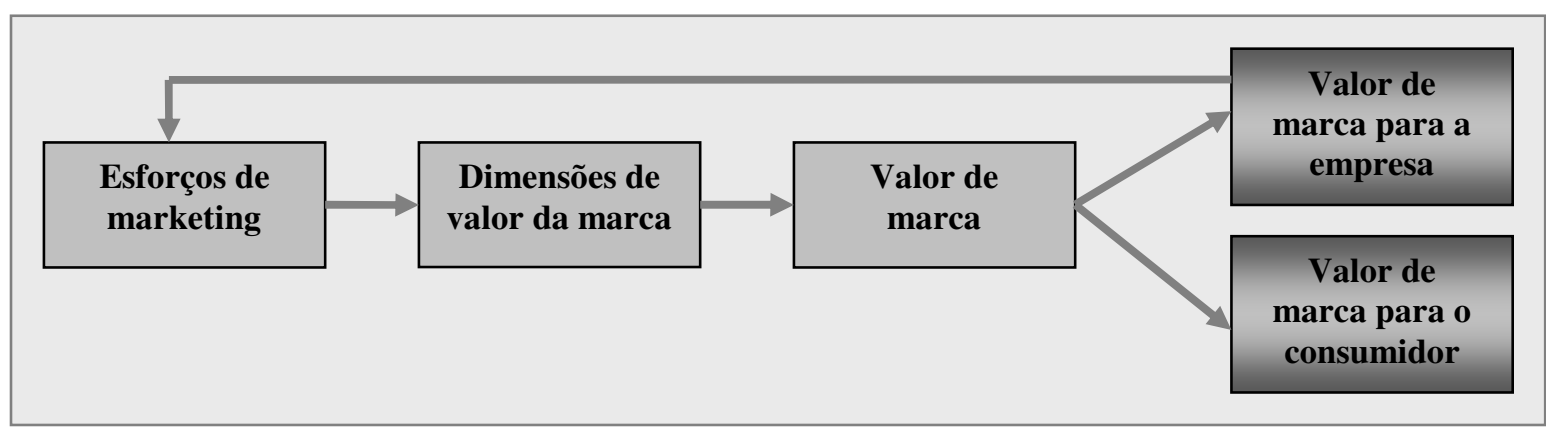

Figura 2 - Expansão do modelo conceitual de valor de marca Fonte: Yoo et al. (2000)

No modelo de Yoo et al. (2000), os esforços de marketing empreendidos pela empresa são antecedentes das dimensões de valor da a marca propostas por Aaker (1996). Dessa forma, os esforços de marketing podem influenciar a criação, manutenção e expansão do valor 
de marca das empresas, o que, por sua vez, pode repercutir nos investimentos em marketing. Ou seja, para Yoo et al. (2000), o valor da marca impacta tanto o valor para a empresa quanto o valor para o consumidor, e sua criação depende tanto de esforços da empresa quanto das perspectivas dos clientes.

Já Raggio e Leone (2007) propõem um novo modelo conceitual que estabelece brand equity e brand value como dois construtos distintos. Brand equity modera o impacto das atividades de marketing nas ações do consumidor, implica um foco baseado no consumidor e representa um dos muitos fatores que contribuem para o brand value, o qual os autores definem como valor de venda ou de substituição da marca, o que implica uma perspectiva baseada na empresa.

Apesar dessas distinções de definições, Shankar, Azar e Fuller (2007) abordam o valor da marca tanto pela perspectiva do consumidor quanto pela da firma, utilizando o mesmo termo, brand equity, apenas sinalizando as perspectivas distintas.

\footnotetext{
"Do ponto de vista do consumidor, o brand equity sinaliza credibilidade, melhorando a percepção dos consumidores sobre a marca e aumentando a confiança nas chamadas da marca, levando a menores custos de informação, menor risco percebido, menor custo de pensamento e maior utilidade para a marca (ERDEM; SWAIT, 1998; ERDEM; SWAIT; VALENZUELA, 2006; SHUGAN, 1980). De uma perspectiva da firma, brand equity permite à firma alavancar a reputação de sua marca para aliviar problemas de assimetria de informação em outros mercados e permite a alta qualidade das marcas para estender a outros mercados (CABRAL, 2000)" (SHANKAR; AZAR; FULLER, 2007, p.3).
}

Nota-se que distintos estudiosos atribuem diferentes conceitos e terminologias sobre o valor da marca, dependendo principalmente da perspectiva que adotam. Muitas vezes brand equity é utilizado quando se trata do valor da marca segundo a perspectiva do consumidor, já brand value ou brand valuation é usualmente empregado em trabalhos sob a perspectiva da contabilidade, financeira ou da firma. Entretanto, vários autores utilizam o termo brand equity para ambas as perspectivas sobre o valor da marca. Trinta (2006) ressalta que ainda não existe um modelo que não seja passível de contestações. Dessa forma, o presente trabalho optou por utilizar as terminologias utilizadas nos trabalhos originais, pois não objetiva determinar um conceito de valor da marca mais adequado, mas sim fomentar discussões sobre o assunto, visando futuras pesquisas no Brasil.

A despeito da ambiguidade de definições sobre o valor da marca existentes no campo teórico, Cortês-Real (2006) assinala que tal situação apresenta impacto positivo para a área prática (gerencial), na medida em que chama a atenção das organizações sobre a necessidade de se focarem nas estratégias de marca e analisarem os modelos mais adequados para avaliar 
O valor da marca: conceitos, abordagens e estudos no Brasil

um dos seus ativos mais valiosos. O tema da avaliação e mensuração da marca é tratado no item a seguir.

\subsection{Mensuração do valor da marca}

Como visto na seção anterior, o conceito de valor da marca não é um consenso, nem mesmo dentro da disciplina de marketing. Kapferer (2004b) afirma que, via pesquisa acadêmica sobre o assunto, já foram inventariados mais de 26 diferentes modalidades de medição do brand equity. Para Keller (1998), existem diferentes formas de apresentação devido a diferentes propósitos. Como consequência, as abordagens e modelos de mensuração do valor da marca também se apresentam com diversidade.

De acordo com Keller (1993), existem duas motivações gerais para o estudo do brand equity. Uma é baseada na motivação financeira de estimar o valor da marca mais precisamente, com propósitos contábeis (em termos de avaliação de ativos para o balanço patrimonial), para funções, aquisições ou fins de alienação. A segunda razão para estudar o brand equity recai sobre a estratégia baseada na motivação para melhorar a produtividade de marketing.

Nesse contexto, a mensuração do valor da marca é extremamente relevante para saber se os investimentos em marca dão resultado e geram retornos adequados, para assim justificar suas ações pelo marketing (YEUNG; RAMASAMY, 2007). Por um longo tempo, a falta de explanações e relatórios financeiros por parte do marketing "têm minado a credibilidade do marketing, ameaçado a permanência do marketing na firma e, ainda, ameaçado a existência do marketing como uma distinta capability dentro da firma" (RUST et al., 2004b; MADDEN; FEHLE; FOURNIER, 2006). Dessa forma, o marketing tem se esforçado para criar métricas que se relacionem com desempenhos financeiros, entre elas o valor da marca.

A primeira avaliação de marcas com finalidade financeira de que se tem registro ocorreu em 1984, quando o empresário australiano Rupert Murdoch mandou estimar o valor das marcas de sua companhia - títulos de jornais e revistas - para incluir nos balanços contábeis (PINHO, 1996 apud STRINGHETTI, 2001; TARSITANO; NAVACINSK, 2004). A Interbrand Group, uma consultoria inglesa especializada na administração de marcas, foi a primeira a especificar critérios para determinar o valor das marcas. Seguindo a solicitação de seu cliente, a Ranks Hovis McDougall, empresa do setor alimentício, desenvolveu um sistema que lhe permitia avaliar, em libras, o "peso" das marcas (PINHO, 1996 apud TARSITANO; NAVACINSK, 2004). Atualmente, a Interbrand (2006) estima o valor da marca como "a divisão dos futuros fluxos de caixa relativos à marca previstos por analistas e julgadores”. 
Muitas abordagens têm sido propostas para estimar o brand equity (SHANKAR; AZAR; FULLER, 2007), tanto sob a óptica do consumidor quanto financeira. O valor da marca sob a perspectiva do consumidor pode ser mensurado através do modelo clássico de Keller (1998), o qual realizou uma revisão teórica sobre o tema (conforme aponta o Quadro 1). Segundo Kelller (1993), existem duas abordagens para medir o brand equity baseado no consumidor. A abordagem indireta procura acessar os recursos potenciais do brand equity pela mensuração do conhecimento da marca (brand awareness e brand image). A abordagem direta tenta medir o brand equity baseado no consumidor pelo acesso mais direto do impacto do conhecimento da marca na resposta do consumidor para diferentes elementos do programa de marketing da firma (KELLER, 1993).

De acordo com a Interbrand (2004), o entendimento, interpretação e mensuração dos indicadores de brand equity segundo a perspectiva do consumidor são extremamente relevantes, pois eles representam as principais medidas do comportamento de compra dos consumidores do qual o sucesso das marcas depende. "Entretanto, a menos que eles estejam integrados com um modelo econômico, eles são insuficientes para acessar o valor econômico das marcas" (INTERBRAND, 2004, p.7).

O valor da marca pela óptica financeira apresenta, de acordo com Trinta (2006), seis métodos de avaliação financeira das marcas. Entretanto, segundo Ambler (2003, p.54), “um grande número de modelos são utilizados para avaliar as marcas, mas o principal é o que envolve os futuros fluxos de caixa descontados". A Interbrand (2004) segue essa linha de pensamento, afirmando que os métodos de avaliação recomendados são as abordagens de fluxo de caixa descontado (DCF) e de valor de mercado.

Vargas Neto (2003) observa essas distintas percepções sobre o valor da marca. Segundo o autor, existem dois caminhos para o estudo de brand equity: um relacionado à mensuração para a consideração no valor de mercado da empresa (FELDWICK, 1996), que trata do valor financeiro da marca; e outra sobre a mensuração para a criação do valor de brand equity ao consumidor (KELLER, 1993; FELDWICK, 1996; VARGAS NETO, 2003). $\mathrm{O}$ autor destaca que ambos os caminhos são relacionados, visto que o brand equity baseado no consumidor (consumer based brand equity) é a base para construir uma marca sólida.

Shankar, Azar e Fuller (2007) buscaram desenvolver um modelo inovador para estimar e administrar o brand equity, para multicategorias de marcas, que utilizasse uma combinação de survey com os clientes e medidas financeiras para cada categoria de produtos. Para a obtenção desse modelo, os autores revisaram a literatura existente, levantando as distintas abordagens utilizadas por vários estudiosos, conforme mostra o Quadro 2. 
Princípio

Receitas premium calculadas como as diferenças incrementais das receitas da marca sobre a receita de um rótulo determinado.

Gastos de marca são amortizados sobre um suposto horizonte, e o que não é amortização é tratado como brand equity. DCF e retornos excedentes (adicionais) diferenciam-se em firmas genéricas.

Medidas econômicas das diferenças entre o lucro da marca e um produto genérico.

Porção do fluxo de caixa atribuível à marca relativa às variáveis do mix de marketing.

Estimativa econométrica do preço premium através de uma função de regressão hedônica.

Estimativa econométrica do preço premium através de uma função de regressão hedônica.

Estimativa da participação futura relacionada à marca e previsões de fluxos de caixa pelos analistas

Estimativa da qualidade percebida e índice do valor intangível da função da utilidade da marca.

Survey baseada na estimativa de componentes atribuídos e não atribuídos ao brand equity em termos de market share e preços premiums atribuídos a marca.

Proporção do resultado do brand equity (regredidos em fontes tais como a consciência, a consideração e as associações) para a marca focal sobre a soma dos resultados para todas as marcas.

Regressão baseada na decomposição da capitalização do mercado da firma devido aos intangíveis tais como os ativos da marca.

Estimativa dos efeitos específicos da marca como componentes da preferência de marca em modelos multiatribuídos.

Estimativa do preço e volume premium da função de utilidade da marca.

Estimativa do preço premium da função de utilidade da marca.

Estimativa da força da marca e estatura da marca (duas dimensões do brand equity).

Estimativa do fluxo de caixa incremental atribuível à marca em cada categoria nas quais a marca compete. Estudo do relacionamento entre brand equity e propaganda, assim como do relacionamento entre brand equity e valor do acionista.
Dados de variáveis de vendas semanais e promoções de vendas de uma cadeia de minimercados.

Nenhum dado empírico.

Dados de auditorias de lojas da

Nielsen e dados retirados de armazéns pela SAMI Burke.

Survey com consumidores e dados financeiros.

Dados de preços

\section{Dados de preços}

Avaliação de experts, fluxos de caixa projetados.

Dados do scanner panel.

Survey com consumidores.

Survey com consumidores e entrevistas face-to-face.

Relatórios anuais publicados.

Survey com consumidores.

Survey com o consumidores.

Survey com consumidores.

Survey com consumidores.

Survey com consumidores, dados financeiros e medidas de marketing.

\section{Autor}

Ailawadi, Lehmann, e Neslin (2003)

Damodaran (2006)

Dubin (1998)

Fischer (2004)

Hjorth-Anderson (1984)

Holbrook (1992)

Interbrand (2006)

\section{Kamakura e}

Russell (1993)

Park e Srinivasan (1994)

\section{Roberts, Morrison,}

Chandrasekharan,

e Gordon (2004)

Simon e Sullivan (1993)

Srinivasan (1979)

Srinivasan, Park e Chang (2005)

Swait et al. (1993)

Young and Rubicam (2006)

Shankar, Azar e Fuller (2007)

Quadro 2 - Sumário dos modelos selecionados para estimar o brand equity Fonte: Shankar, Azar e Fuller (2007). 
Conforme exposto no Quadro 2, nota-se que "existem vários modelos que computam o valor da marca, sendo que vários foram desenvolvidos por práticos" (VILLANUEVA; HANSSENS, 2007, p.7). Entretanto, Trinta (2006) ressalta que, embora existam várias formas de mensuração, nenhuma forma de cálculo possui plena aceitação. Até os modelos exclusivamente financeiros não apresentam unanimidade, uma vez que os padrões de avaliação (de patrimônio) do intangível variam segundo os países, empresas, setores, ambiente competitivo e conjuntura. Além disso, a existência de diversas abordagens também se deve à existência de distintos objetivos relacionados à utilização do valor da marca.

Mesmo assim, o presente estudo acredita que a união de informações relacionadas à percepção do cliente com dados financeiros permite a mensuração do valor da marca de forma mais completa. Isto porque modelos exclusivamente financeiros desprezam a opinião e o comportamento dos consumidores em relação à marca. Já os modelos baseados apenas no consumidor, de acordo com Interbrand (2004), não fornecem uma relação clara entre indicadores específicos de marketing e desempenho. Uma marca pode ter um desempenho forte de acordo com esses indicadores, mas ainda falhar em criar valor financeiro e valor ao acionista. Para Guzmán (2004, p. 3), “as marcas falham em obter o seu potencial de criação de valor quando os gestores perseguem estratégias que não são orientadas à maximização do valor do acionista”.

A mensuração através da união de tais modelos seria capaz de satisfazer tanto os imperativos de informações dos profissionais das áreas de marketing e finanças quanto as necessidades dos gestores estratégicos e acionistas. Se os profissionais de marketing conseguirem assegurar que o valor da marca está participando da criação de valor ao acionista e relacionar o valor da marca à lucratividade, o marketing aumentará sua credibilidade, pois será como ligar os esforços de marketing à lucratividade (YEUNG; RAMASAMY, 2007).

\section{DESENVOLVIMENTO DA PESQUISA}

Realizar um levantamento dos estudos brasileiros relativos ao valor da marca permite fazer um apanhado histórico das pesquisas realizadas, das abordagens utilizadas e da evolução desse tema no Brasil. Uma vez que esse campo de estudo ainda pode desenvolver-se no país (MARTINS, 2007), o presente trabalho busca auxiliar a direcionar potenciais caminhos para futuras pesquisas no Brasil.

Para tanto, adotou-se a técnica de desk research (MALHOTRA, 2002), buscando a compreensão do tema do valor da marca, com a realização de uma pesquisa bibliográfica sobre os conceitos, construtos e abordagens relativas. Além disso, foi realizado um 
O valor da marca: conceitos, abordagens e estudos no Brasil

levantamento entre alguns dos principais congressos e periódicos de Administração do Brasil, procurando nos títulos e nos resumos dos artigos pelos termos: valor da marca, brand equity e brand value.

O critério para a escolha dos congressos e periódicos foi: ser uma publicação nacional atinente à área de Administração, com publicações relativas à área de marketing, avaliados pelo Qualis/Capes, ano-base 2008, entre A1 a B1. Assim, foram realizados levantamentos nos periódicos: Revista de Administração Contemporânea (RAC), RAC eletrônica, Brazilian Administration Review (BAR), Revista de Administração de Empresas (RAE), RAE eletrônica, RAE - especial Minas Gerais e Revista de Administração Mackenzie (RAM).

Além disso, foram realizadas pesquisadas nas publicações dos congressos da Associação Nacional de Pesquisa em Administração (ANPAD): Encontro Nacional da ANPAD (ENANPAD), Encontro de Marketing da ANPAD (EMA), Encontro de Estudos Organizacionais (EnEO) e Encontro de Estudos em Estratégia (3 Es).

O levantamento foi realizado a partir da data de publicação das primeiras edições disponíveis online nos sites dos periódicos e congressos até fevereiro de 2010. Em cada uma dessas publicações, analisaram-se os artigos publicados dentro dos seguintes períodos (ver Quadro 3):

\begin{tabular}{|c|c|c|c|}
\hline \multirow{2}{*}{ Publicações } & \multicolumn{2}{|c|}{ Período analisado por publicação } & \multirow{2}{*}{$\begin{array}{c}\text { Quantidade de artigos sobre valor da } \\
\text { marca }\end{array}$} \\
\hline & Ano inicial & Ano fim & \\
\hline ENANPAD & 1997 & 2010 & 19 \\
\hline EMA & 2004 & 2010 & 4 \\
\hline $3 \mathrm{Es}$ & 2003 & 2010 & 1 \\
\hline ENEO & 2000 & 2010 & 0 \\
\hline $\begin{array}{l}\text { Revista de Administração } \\
\text { Contemporânea (RAC) }\end{array}$ & 1997 & 2010 & 1 \\
\hline RAC eletrônica & 2007 & 2010 & 0 \\
\hline $\begin{array}{l}\text { Brazilian Administration } \\
\text { Review (BAR) }\end{array}$ & 1997 & 2010 & 1 \\
\hline $\begin{array}{l}\text { Revista de Administração } \\
\text { de Empresas (RAE) }\end{array}$ & 1961 & 2010 & 1 \\
\hline $\begin{array}{l}\text { Revista de Administração } \\
\text { de Empresas (RAE) - } \\
\text { eletrônica }\end{array}$ & 2002 & 2010 & 1 \\
\hline $\begin{array}{l}\text { Revista de Administração } \\
\text { Mackenzie (RAM) }\end{array}$ & 2000 & 2010 & 2 \\
\hline
\end{tabular}

Quadro 3 - Período analisado por publicação

Destaca-se que existem outros periódicos nacionais de Administração, classificados no Qualis/Capes entre A1 e B1 (por exemplo: Gestão \& Produção, Revista de Administração Pública, Produção, Revista Brasileira de Finanças, Revista Contabilidade \& Finanças, Revista 
de Economia Contemporânea etc.), em cujas edições se chegaram a realizar pesquisas. Contudo, tais periódicos não apresentavam artigos relativos a valor da marca, e alguns sequer apresentavam publicações atinentes a área de Marketing.

\section{ESTUDOS SOBRE O VALOR DA MARCA NO BRASIL}

Os trabalhos realizados no Brasil atinentes ao valor da marca - encontrados neste levantamento - estão brevemente descritos no Quadro 4. Destaca-se que foram encontrados outros artigos com assuntos atinentes a marca, mas sem relação direta com a sua valoração.

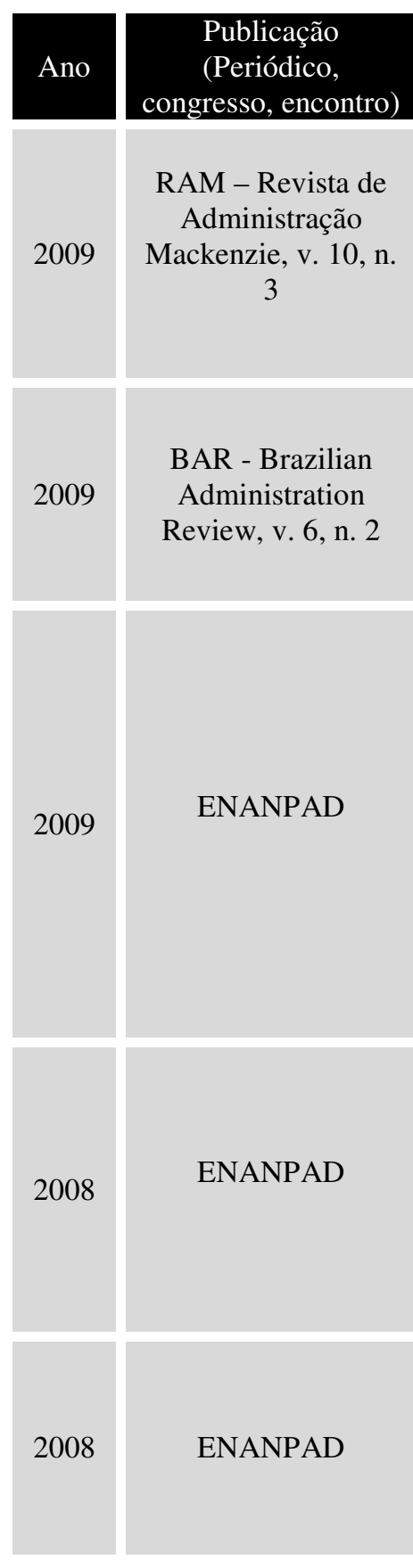

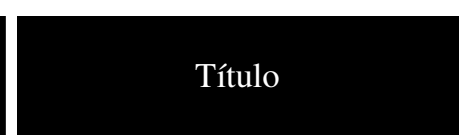

O valor dos valores: avaliação de uma marca global por meio dos diversos Brasis culturais

Brand equity evolution: a system dynamics model

O valor da marca e o valor ao acionista em empresas brasileiras

Consumer-based brand equity: teste empírico de modelo de dimensões formadoras do valor da marca na perspectiva do consumidor

O valor dos valores: uma abordagem exploratória do cerne da cultura e da sua influência na avaliação de uma marca

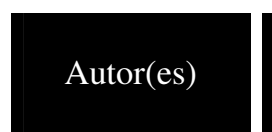

Edar da Silva Añaña,

Walter Meucci Nique

Edson

Crescitelli,

Júlio Bastos

Figueiredo

Marta Olivia

Rovedder de

Oliveira,

Fernando Bins

Luce

Luiz Sergio

Costa, Victor

Manoel Cunha

de Almeida

Edar da Silva

Añaña, Walter

Meucci Nique

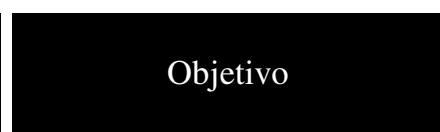

Explorar as influências dos valores pessoais e de outros elementos da cultura brasileira na avaliação de uma marca de alcance mundial, por meio de quatro subculturas regionais.

Desenvolver um modelo sistemático de fatores que determinam o valor da marca (brand value) ao longo do tempo e similar a este modelo.

Comparar o desempenho, no mercado acionário brasileiro, do portfólio de empresas com reconhecido valor da marca - apontado pelos rankings de marcas mais valiosas brasileiras publicados pela Interbrand com outros portfólios de empresas com ações listadas na Bolsa de Valores do Estado de São Paulo.

$\mathrm{O}$ estudo investigou a importância das dimensões formadoras do valor da marca na perspectiva do consumidor, mediante o teste empírico do modelo proposto por Yoo e Donthu (2001).

Explorar as influências dos valores humanos e de outros elementos da cultura brasileira, na avaliação de uma marca de alcance mundial. 
O valor da marca: conceitos, abordagens e estudos no Brasil

\begin{tabular}{|c|c|c|c|c|}
\hline 2008 & $\begin{array}{l}\text { RAE eletrônica, v. } 7 \text {, } \\
\text { n. } 2\end{array}$ & $\begin{array}{l}\text { Avaliação de marcas: uma } \\
\text { aplicação ao caso Bombril }\end{array}$ & $\begin{array}{c}\text { Érica Saião } \\
\text { Caputo, } \\
\text { Marcelo } \\
\text { Alvaro da } \\
\text { Silva Macedo, } \\
\text { Heloísa } \\
\text { Guimarães } \\
\text { Peixoto } \\
\text { Nogueira }\end{array}$ & $\begin{array}{l}\text { A pesquisa objetivou valorar } \\
\text { a marca Bombril. A } \\
\text { principal premissa do } \\
\text { modelo utilizado é que uma } \\
\text { marca forte permite a prática } \\
\text { de preços superiores aos } \\
\text { preços de empresas que não } \\
\text { detêm o mesmo } \\
\text { reconhecimento de marca. }\end{array}$ \\
\hline 2008 & EMA & $\begin{array}{l}\text { Avaliação de marcas: uma } \\
\text { aplicação ao caso Bombril }\end{array}$ & $\begin{array}{c}\text { Érica Saião } \\
\text { Caputo, } \\
\text { Marcelo } \\
\text { Alvaro da } \\
\text { Silva Macedo, } \\
\text { Heloísa } \\
\text { Guimarães } \\
\text { Peixoto } \\
\text { Nogueira }\end{array}$ & $\begin{array}{l}\text { A pesquisa objetivou valorar } \\
\text { a marca Bombril. A } \\
\text { principal premissa do } \\
\text { modelo utilizado é que uma } \\
\text { marca forte permite a prática } \\
\text { de preços superiores aos } \\
\text { preços de empresas que não } \\
\text { detêm o mesmo } \\
\text { reconhecimento de marca. }\end{array}$ \\
\hline 2008 & EMA & $\begin{array}{l}\text { Influências do valor da marca } \\
\text { da Petrobras BR: um estudo } \\
\text { com consumidores do } \\
\text { segmento de combustíveis }\end{array}$ & $\begin{array}{c}\text { Rogério } \\
\text { Ramalho da } \\
\text { Silva, Robson } \\
\text { Roberto } \\
\text { Amstalden, } \\
\text { Tom Pierre } \\
\text { Fernandes } \\
\text { Silva }\end{array}$ & $\begin{array}{l}\text { Avaliar o quanto o valor de } \\
\text { marca da Petrobras BR - } \\
\text { segmento de combustíveis - } \\
\text { é influenciado pelos } \\
\text { atributos: lealdade à marca, } \\
\text { conhecimento da marca, } \\
\text { qualidade percebida e } \\
\text { associações à marca, através } \\
\text { da atitude dos consumidores } \\
\text { nos estados do Rio de } \\
\text { Janeiro e São Paulo. }\end{array}$ \\
\hline 2008 & EMA & $\begin{array}{c}\text { Valor da marca: conceitos, } \\
\text { abordagens e estado da arte } \\
\text { no Brasil }\end{array}$ & $\begin{array}{l}\text { Marta Olivia } \\
\text { Rovedder de } \\
\text { Oliveira }\end{array}$ & $\begin{array}{c}\text { O estudo visa verificar o } \\
\text { estado da arte relativo ao } \\
\text { tema valor da marca no } \\
\text { Brasil. }\end{array}$ \\
\hline 2008 & ENANPAD & $\begin{array}{l}\text { Valor de marca na nova } \\
\text { lógica de serviços }\end{array}$ & $\begin{array}{l}\text { Lívia Castro } \\
\text { D’Avila, } \\
\text { Cláudio } \\
\text { Damacena, } \\
\text { Ivan Lapuente } \\
\text { Garrido }\end{array}$ & $\begin{array}{l}\text { O objetivo deste artigo é } \\
\text { propor um modelo } \\
\text { conceitual de antecedentes } \\
\text { do valor de marca na nova } \\
\text { lógica de serviços. }\end{array}$ \\
\hline 2008 & ENANPAD & $\begin{array}{l}\text { Marcas próprias e valor da } \\
\text { marca: o estudo de caso da } \\
\text { marca própria Carrefour }\end{array}$ & $\begin{array}{c}\text { Fernanda } \\
\text { Borges Murad, } \\
\text { Daniela Ferro } \\
\text { Torres }\end{array}$ & $\begin{array}{l}\text { O presente estudo reúne } \\
\text { discussões sobre o tema } \\
\text { valor da marca, tomando } \\
\text { como base de análise a } \\
\text { marca própria Carrefour. }\end{array}$ \\
\hline 2007 & $\begin{array}{l}\text { RAC - Revista de } \\
\text { Administraçãa } \\
\text { Contemporânea. v. } \\
\text { 11, Mai -Jun. }\end{array}$ & $\begin{array}{l}\text { Compreendendo os valores } \\
\text { das marcas: aplicação da lista } \\
\text { de valores em diferentes } \\
\text { indústrias }\end{array}$ & $\begin{array}{c}\text { André Luiz } \\
\text { Maranhão de } \\
\text { Souza Leão; } \\
\text { Arcanjo F. de } \\
\text { Souza Neto; } \\
\text { Sérgio C. B. de } \\
\text { Mello }\end{array}$ & $\begin{array}{l}\text { Objetiva verificar e avaliar } \\
\text { os valores percebidos pelos } \\
\text { consumidores nas marcas, } \\
\text { tomando como referência o } \\
\text { conceito de personalidade de } \\
\text { marca. Utiliza a lista de } \\
\text { valores LOV. }\end{array}$ \\
\hline 2007 & ENANPAD & $\begin{array}{l}\text { "Valor de marca" para quem? } \\
\text { - rumo a uma teoria da } \\
\text { significação das marcas pelos } \\
\text { consumidores }\end{array}$ & $\begin{array}{l}\text { André Luiz M. } \\
\text { de Souza Leão }\end{array}$ & $\begin{array}{l}\text { Apresentar um modelo de } \\
\text { simulação para representar a } \\
\text { evolução, o qual é baseado } \\
\text { no conceito de brand equity } \\
\text { desenvolvido por Aaker \& } \\
\text { Joachimsthaler (2000). }\end{array}$ \\
\hline 2007 & ENANPAD & Using the system dynamic & Júlio César & Propõe uma teoria em que \\
\hline
\end{tabular}


Marta Olivia Rovedder de Oliveira \& Fernando Bins Luce

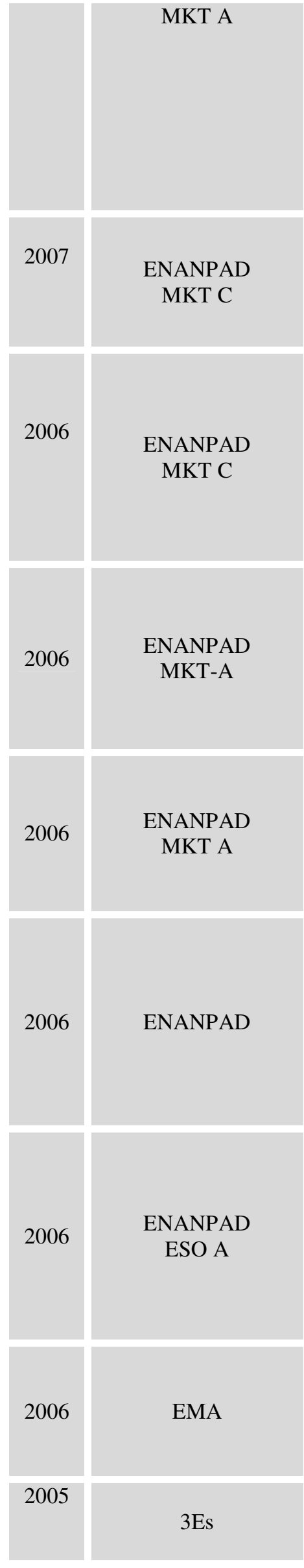

methodology to study the
brand equity evolution
Relações entre a reputação e
o valor da marca no setor
automotivo

Brand equity baseado no consumidor:

desenvolvimento e validação de um instrumento de mensuração no setor automotivo

Nem tudo que reluz é ouro: um estudo da interferência da força da marca na formação dos preços com o uso de testes de correlação e análise de conglomerados

Imagem do canal de distribuição como fator antecedente das dimensões da percepção do valor da marca na perspectiva do consumidor

A sensibilidade ao preço de venda versus brand equity em mercados de produtos de alto giro

The value relevance of intangible capabilities deployment: the role of firm life cycle

Mensuração de brand equity baseado no consumidor: avaliação de escala multidimensional.

Avaliação estratégica de ativos intangíveis: uma proposta de modelagem dea

Bastos de
Figueiredo;
Edson
Crescitelli

Daniela Ferro de Oliveira

Cid Gonçalves Filho

\section{Roberto \\ Brasileiro \\ Paixão;}

Adriano Leal

Bruni;

Rodrigo

Ladeira

\section{Luiz Sergio} Costa;

Victor Manoel

Cunha de

Almeida

Paulo

Burlamaqui;

Egon Barbosa

Eduardo

Kazuo Kayo;

Leonardo

Fernando Cruz

Basso; Joan D.

Penner-Hahn

\section{Alcivio Vargas} Neto;

Fernando Bins Luce

Marcelo

Alvaro da

Silva Macedo; apresentam a significação das marcas como advinda dos consumidores, na medida em que estes fazem uso das mesmas enquanto signos em suas vidas cotidianas por meio da linguagem.

Busca reunir duas dimensões, a Reputação e o Valor da Marca, e avaliar sua intensidade no setor automotivo.

Visa identificar as bases de diferenciação da marca para os consumidores de automóveis, avaliando assim

o brand equity, e busca desenvolver uma escala de medição e avaliação do valor da marca para o consumidor.

Analisar as possíveis relações existentes entre a força da marca e a cobrança de preços superiores, denominados preços prêmios.

Discutir a relevância da imagem do canal de distribuição na formação da percepção do valor da marca na perspectiva do consumidor.

Saber qual é o nível ótimo de força da marca e quando se deve investir em uma marca. Relativo à sensibilidade ao preço em mercados de alto giro, em contraposição à força de marca dos competidores.

Analisar a relação entre investimentos em capabilities intangíveis (inovação e criação de marca) e valor de criação, levando em consideração as diferentes fases de vida da firma.

O objetivo deste estudo é avaliar a escala multidimensional para mensuração de brand equity baseado no consumidor.

A proposta metodológica busca sintetizar em um único parâmetro (Índice de 
O valor da marca: conceitos, abordagens e estudos no Brasil

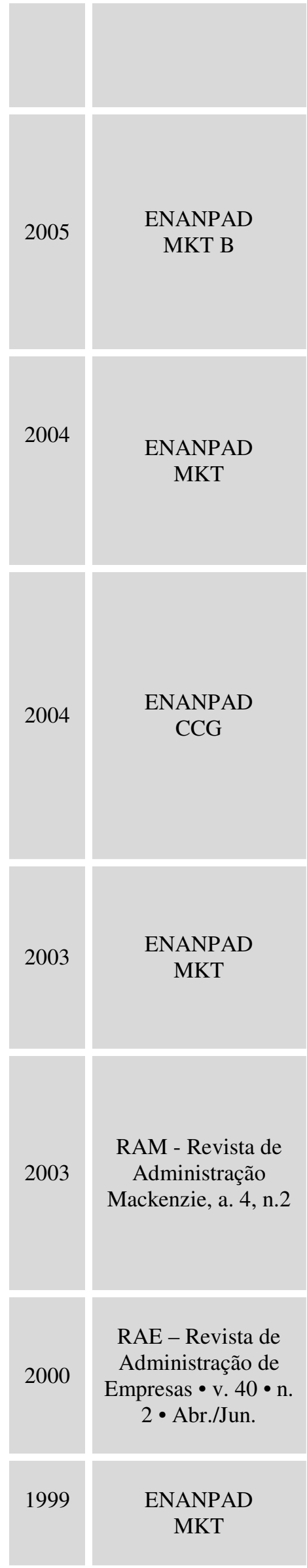

aplicada ao valor da marca e performance organizacional de bancos no mercado brasileiro

Marketing de gerações: construção e teste de escala para avaliação da marca de refrigerante Coca-Cola por jovens na fase de transição entre as gerações $\mathrm{x}$ e $\mathrm{y}$

Comunicação integrada de marketing em empresas de tecnologia da informação: realidade ou utopia no estabelecimento do valor de marca?

Características estratégicas dos ativos intangíveis e o desempenho econômico da empresa

Descobrindo os valores das marcas: aplicação da lista de valores (LOV) em diferentes setores

Que valores estão na moda? Achados muito além do efêmero

Modelos de avaliação de marca

\footnotetext{
Brand equity and the internet: the impact of internet presence sites in the development and strength of
}

\section{Murilo \\ Alvarenga \\ Oliveira}

Fabiano Notti

Laux;

Stefânia

Ordovás de

Almeida;

Rita de Cássia de Faria

Pereira

Shirley Arruda

Santana

Marcelo

Monteiro

Perez;

Rubens Fama

André Luiz

Maranhão de

Souza Leão;

Arcanjo

Ferreira de

Souza Neto

Sérgio C.

Benício de

Mello, André

1. Maranhão

Leão, Arcanjo

F. de Souza

Neto

Maria João

Soares Louro

Alexandra
Lopes da
Cunha; Marcus
V. M. da

Performance Empresarial IPE) indicadores de diversas naturezas na análise de desempenho organizacional.

\section{Identificar os principais} motivadores de escolha, emocionais e racionais, e fatores de influência do comportamento do consumidor brasileiro frente às distintas opções de marcas no segmento de produtos alimentícios.

Identificar se e como a comunicação integrada de marketing (CIM) é utilizada por empresas de TI, e de que forma ela contribui para o estabelecimento do valor de marca destas empresas, na perspectiva de seus gestores.

Apresentar as características estratégicas dos ativos intangíveis e verificar a possível existência de uma correlação entre uma maior presença de ativos intangíveis na estrutura de ativos da empresa e um desempenho econômico superior e maior criação de valor aos acionistas.

\section{Objetiva descobrir os} "valores pessoais" das marcas, tomando como referência o conceito de "personalidade de marca". Para isto, foi utilizada a lista de valores LOV.

Identificar os valores de duas marcas do setor de moda por meio da percepção dos consumidores sobre que valores são esses (imagem), como estas marcas deveriam se mostrar para seus clientes (identidade) (KAPFERER, 1997).

Face à multiplicidade de conceitos e modelos de avaliação, são contrastadas e sintetizadas as abordagens acadêmicas e empresariais dominantes.

Foca-se na influência dos
sites da Internet no
desenvolvimento e
manutenção de associações




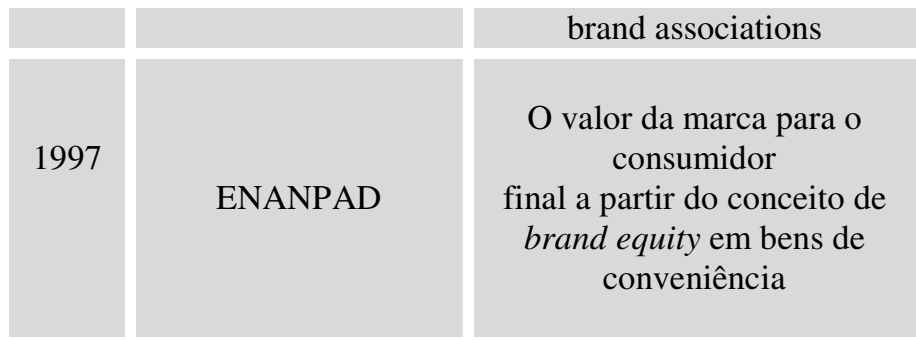

Quadro 4 - Publicações relacionadas ao valor da marca

Cunha Jr.
Alexandra
Lopes da
Cunha; Luis
Roque
Klering;
Fernando Bins
Luce

Além dos periódicos e congressos analisados, também foram encontrados outros artigos brasileiros que abordam a questão do valor da marca, com o de Tarsitano e Navacinsk (2004), na publicação “Comunicação \& Sociedade”, trabalho de caráter teórico-conceitual. Da mesma forma o artigo de Trinta (2006), apresentado no $3^{\circ}$ Congresso de Comunicação e Marketing/FGV-CENPRO, também de caráter teórico-conceitual, mas que trata especificamente de métodos financeiros para avaliar as marcas. Na Revista Eletrônica de Administração (READ), também foi publicado o artigo de Pereira (2006) sobre a construção e teste de escala para avaliação da marca de um refrigerante.

Dentre as pesquisas observadas, verifica-se que muitas lidam com o brand equity baseado no consumidor, tais como Lopes, Klering e Luce (1997), Laux, Almeida e Pereira (2005), Burlamaqui e Barbosa (2006), Vargas Neto e Luce (2006), Pereira (2006), Gonçalvez Filho (2006), Costa e Almeida (2006), Figueiredo e Crescitelli (2007), Oliveira (2007), Silva, Amstalden e Fernandes Silva (2008), Murad e Torres (2008), D’Avila, Damacena e Garrido (2008) e Costa e Almeida (2009). Outras ainda têm enfoque nas percepções do consumidor quanto à valoração de marcas, segundo uma abordagem mais relacionada à área de comportamento do consumidor, e não buscam quantificar financeiramente o valor da marca: Leão e Souza Neto (2003), Leão, Souza Neto e Mello (2007), Añaña e Nique (2008) e Añaña e Nique (2009). Além desses estudos, durante o levantamento foram encontradas pesquisas sobre avaliações de marca de produtos realizadas à luz da teoria da cadeia meios fins de Gutman (1982). Tais casos, apesar de apresentarem valoração de marcas, não tratam exatamente dos conceitos de brand equity ou brand value, escopo deste estudo.

Dessa forma, percebe-se que ainda há espaço para mais estudos do valor da marca segundo uma linha de marketing estratégico, e nota-se uma carência de pesquisas que enfoquem o valor da marca segundo a perspectiva da firma. Dentre o levantamento foram encontrados trabalhos que tratam o valor da marca como parte dos ativos intangíveis de uma empresa, com uma visão mais financeira, como as pesquisa de Perez e Fama (2004), Macedo e Oliveira (2005), Crescitelli e Figueiredo (2009) e Oliveira e Luce (2009). Além destes, o trabalho de Santana (2004) apresenta uma visão mais gerencial do valor da marca; entretanto 
O valor da marca: conceitos, abordagens e estudos no Brasil

nota-se que a abordagem do valor da marca baseado na firma e a observação de aspectos financeiros podem ser mais exploradas. Cabe destacar que a verificação da relação entre o valor da marca e o desempenho empresarial, seja lucratividade ou valor ao acionista, não é uma carência exclusiva das publicações brasileiras. Para Madden, Fehle e Fournier (2006), enquanto os estudiosos têm sustentado a um bom tempo que as atividades de marketing que se dedicam à fortificação da marca criam valor ao acionista, ainda falta forte evidência empírica capaz de sustentar essa relação.

Nesse mesmo cenário, percebe-se ainda a quantidade de estudos de caráter teóricoconceitual a respeito do valor da marca, como Da Cunha e Cunha Jr. (1999), Louro (2000), Tarsitano e Navacinsk (2004), Trinta (2006), Costa e Almeida (2006), Leão (2007) e Oliveira (2008), apontando uma oportunidade para a realização de mais estudos de caráter empírico.

Dentre os autores nacionais, destaca-se André Luiz Maranhão de Souza Leão, com quatro publicações, e Fernando Bins Luce, com três publicações relativas a esse tema. Entretanto, o primeiro autor aborda o valor da marca segundo uma linha de comportamento do consumidor, sendo três de seus trabalhos relacionados à lista de valores LOV. Já o segundo autor realiza estudos sobre o brand equity, com uma abordagem mais relacionada ao marketing estratégico.

De uma maneira geral, esse levantamento permite apontar que a pesquisa sobre o valor da marca ainda é incipiente no Brasil, sendo de 1997 o registro mais antigo deste tipo de estudo, uma década após os primeiros trabalhos realizados no mundo dos quais se tem registro. Para se tecer um comparativo, Villaneuva e Hanssens (2007) realizaram uma pesquisa sobre os artigos que abordam o brand equity nos 5 principais journals internacionais, encontrando 39 publicações: Journal of Marketing Research (12 publicações), Marketing Science (11), Journal of Consumer Research (3), International Journal of Research in Marketing (10) e Manangement Science (3). Ressalta-se que tal levantamento não incluiu a busca por brand value, brand valuation e a lista de valores LOV. Ademais, o estudo foi realizado em dezembro de 2006, quatro anos antes da presente pesquisa, justamente o período onde ocorreu um crescimento de publicações no Brasil.

Devido à importância do tema valor da marca e a incipiência da pesquisa no Brasil, percebe-se que ainda há um bom espaço para o aprofundamento dos conhecimentos necessários, tanto para os acadêmicos quanto para os práticos. As poucas publicações existentes, principalmente em periódicos nacionais, podem ser visualizadas como uma oportunidade para os pesquisadores brasileiros iniciarem ou aprofundarem estudos sobre o tema. 


\section{DISCUSSÃO}

De acordo com a revisão da literatura, percebe-se que existem várias abordagens quanto ao valor da marca, as quais diferem conforme o objetivo visado. Em muitos casos, o brand equity e o brand value, ambos com tradução literal para o português como "valor da marca", são tratados como conceitos e construtos distintos (FELDIWICK, 1996; RAGGIO; LEONE, 2007). Nesses estudos, são distinguidas abordagens relativas aos consumidores e aquelas das áreas financeira e contábil, que retratam uma abordagem da firma. Em outros casos, autores como Shankar, Azar e Fuller (2007) buscam unificar as diferentes abordagens em uma única, utilizando dados obtidos com um survey com os consumidores e dados financeiros de mercado. Há ainda aqueles que abordam apenas o termo brand equity e aqueles que abordam apenas brand value, sem fazer distinção.

Apesar da ambiguidade de conceitos e abordagens, esta situação teve, do ponto de vista da gestão da marca, um impacto positivo, na medida em que demonstrou a necessidade das organizações se focalizarem nas estratégias de marca e analisarem os modelos mais adequados para avaliarem um dos seus ativos mais valiosos (CORTÊS-REAL, 2006). De qualquer forma, a mensuração permite uma maior aproximação da área de Marketing com outras áreas da empresa, principalmente com finanças, além de ir ao encontro dos objetivos dos quadros diretores e dos acionistas, ao utilizar informações quantificáveis e possibilitar a demonstração dos resultados de marketing, potencializando o aumento da credibilidade desta área nas empresas.

Do levantamento das pesquisas realizados no Brasil, nota-se que ainda é incipiente a realização de estudos sobre o tema. Nos últimos anos, 2007 e principalmente 2006, houve um crescimento dessas pesquisas, mas ainda há um amplo caminho para esses estudos no Brasil. Muitos estudos são de caráter teórico-conceitual, existindo espaço para avanços em pesquisas de caráter empírico. Também existe uma carência de estudos que relacionem o desempenho da marca ao desempenho empresarial, seja lucratividade ou valor ao acionista. Além disso, nenhum dos estudos trabalhou com a mensuração do valor da marca, observando concomitantemente a perspectiva dos consumidores e a da empresa, com a utilização de dados financeiros, a qual se julga ser a abordagem mais completa. Dessa forma, seria interessante a realização de pesquisas futuras no cenário brasileiro, utilizando-se tais abordagens, que permitiriam uma aproximação de marketing com finanças, gestores e os acionistas, sem deixar de lado uma característica central do marketing: sua relação intrínseca com os clientes. 
O valor da marca: conceitos, abordagens e estudos no Brasil

Nota-se, entre os artigos encontrados, a diversidade de concepções e percepções atinentes ao valor da marca utilizadas. Alguns autores trazem a visão do consumidor sobre o valor, com base na lista de valores LOV. Outros também observam o valor da marca baseado no consumidor, mas com a utilização de conceitos e abordagens de Keller, Aaker, Yoo e Donthu. Há ainda alguns poucos estudos que trabalham com o valor da marca com base na perspectiva da firma, com uma abordagem de cunho financeiro e contábil.

Dentre as limitações deste trabalho, destaca-se o fato de dissertações e teses não terem sido incluídas no levantamento de trabalhos relativos ao tema. Entretanto, crê-se que muitas destas foram representadas pelos artigos oriundos das dissertações e teses dos autores publicados em alguns dos principais congressos e periódicos nacionais.

\section{REFERÊNCIAS}

AAKER, D.A. Building Strong Brands. New York: Free Press, 1996a.

AAKER, D. A. Measuring brand equity across products and markets. Califórnia Management Review, v.38, n.3, p.102-120, Spring 1996b.

AÑAÑ, E. S.; NIQUE, W. M. O valor dos valores: avaliação de uma marca global por meio dos diversos Brasis culturais. Revista de Administração Mackenzie, v. 10, n. 3, 2009.

AÑANA, E. S.; NIQUE, W. M. O valor dos valores: avaliação de uma marca global por meio dos diversos Brasis culturais. XXXII ENANPAD, São Paulo, 2008. Anais... Rio de Janeiro: ANPAD, 2008.

AMA. American Marketing Association's Dictionary. Disponível em: <http://www.marketing power.com./mg-dictionary> Acesso em: jan. 2008.

AMA. American Marketing Association's Dictionary. Disponível em: $<$ http://www.marketingpower.com/_layouts/Dictionary.aspx?dLetter=B >. Acesso em: fev. 2010.

AMBLER, T. Marketing and the bottom line: the marketing metrics to pump up cash flow. 2 . ed. Norfolk: Prentice Hall, 2003. 336p. 
BALDAUF, A.; CRAVENS, K. S.; BINDER, G. Performance consequences of brand equity management: evidence from organizations in the value chain. Journal of Product \& Brand Manangement, v.12, n.4, p.220-236, 2003.

BURLAMAQUI, P.; BARBOSA, E. A sensibilidade ao preço de venda versus brand equity em Mercados de produtos de alto giro. In: XXX ENANPAD, 2006, Salvador. Anais... Salvador: ANPAD, 2006.

CAPUTO, E. S., Macedo, M. A. da S., NOGUEIRA, H. G. P. Avaliação de marcas: uma aplicação ao caso Bombril. In: III EMA, 2008, Curitiba. Anais... ANPAD: Curitiba, 2008.

CAPUTO, E. S., Macedo, M. A. da S., NOGUEIRA, H. G. P. Avaliação de marcas: uma aplicação ao caso Bombril. RAE eletrônica, v. 7, n. 2, 2008.

CRESCITELLI, Edson; FIGUEIREDO, Júlio Bastos. Brand Equity Evolution: a System Dynamics Model. Brazilian Administration Review, v. 6, n. 2, 2009.

CÔRTE-REAL, A. Valor da Marca. Revista Prisma - Revistas das ciências da informação e da comunicação. Faculdade de Economia da Universidade do Porto. ed. 4, p. 3-9, 2006.

COSTA, L. S., ALMEIDA, V. M. C. de. Consumer-based brand equity: teste empírico de modelo de dimensões formadoras do valor da marca na perspectiva do consumidor. XXXII ENANPAD, São Paulo, 2008. Anais... Rio de Janeiro: ANPAD, 2008.

COSTA, L. S.; ALMEIDA, V. M. C. Imagem do Canal de Distribuição como Fator Antecedente das Dimensões da Percepção do Valor da Marca na Perspectiva do Consumidor. In: XXX ENANPAD, 2006, Salvador. Anais... Salvador: ANPAD, 2006.

D’AVILA, L. C.; DAMACENA. C., GARRIDO, I. L. Valor de marca na nova lógica de serviços. XXXII ENANPAD, São Paulo, 2008. Anais... Rio de Janeiro: ANPAD, 2008.

DA CUNHA, A. L.; CUNHA JR, M. V. M. Brand equity and the internet: the impact of internet presence sites in the development and strentgh of brand associations. In: XXIII ENANPAD, 1999, Foz do Iguaçu. Anais... Foz do Iguaçu: ANPAD, 1999.

DA CUNHA, A. L.; KLERING, L.; LUCE, F. B. O valor da marca para o consumidor final a partir do conceito de brand equity em bens de conveniência. In: ENANPAD, 1997, Rio das Pedras. Anais... Rio das Pedras: ANPAD, 1997. 
O valor da marca: conceitos, abordagens e estudos no Brasil

FELDWICK, P. "Do we really need "brand equity?"'. The Journal of Brand Management, v.4, n.1, p.9-28, 1996.

FIGUEIREDO, J. C. B. de; CRESCITELLI, E. Using the System Dynamic Methodology to Study the Brand Equity Evolution. In: XXXI ENANPAD, Rio de Janeiro. Anais... Rio de Janeiro: ANPAD, 2007.

FISCHER, Marc. Valuing brad assets: a cost effective and easy to implement measuramente approach. MSI REPORTS. Working paper series. Issue 2, n. 07 - 002, p. 25-50, 2007.

GONÇALVES FILHO, C. Brand Equity baseado no Consumidor: Desenvolvimento e Validação de um Instrumento de Mensuração no Setor Automotivo. In: XXX ENANPAD, 2006, Salvador. Anais... Salvador: ANPAD, 2006.

GUTMAN, J. A means-end chain model base on consumer categorization processes. Journal of Marketing, v.46, 1982.

GUZMÁN, F. A Brand Building literature review. (Excerpt from PhD Thesis "Brand Building Towards Social Values: Associating to Public Goods"). ESADE - E.S. Administración y Dirección Empresas. Universidad Ramon Llull. 2004.

Interbrand. Brand Valuation: the financial value of the brands. 2004. Disponível em: $<$ http://www.brandchannel.com/images/papers/financial_value.pdf.>. Acesso em: dez. 2007.

Interbrand. Best global brands 2006. Disponível em: <http:www.interbrand.com>. Acesso em: dez. 2007.

KAPFERER, J. O que vai mudar as marcas. Porto Alegre: Bookman, 2004a.

KAPFERER, J. As marcas: capital da empresa. 3.ed. Porto Alegre: Bookman, 2004b.

KAYO, E. K.; BASSO, L. F. C., PENNER-HAHN; J. The Value Relevance of Intangible Capabilities Deployment: the Role of Firm Life Cycle. In: XXX ENANPAD, 2006, Salvador. Anais... Salvador: ANPAD, 2006.

KELLER, K. L. Conceptualizing, measuring, and managing customer-based brand equity. Journal of Marketing, v.57, n.1, p.1-22, jan. 1993. 
KELLER, K. L., L. K.; LEHMANN, D. R. Brand and Branding: Research Findings and Future Priorities. Marketing Science, v.25, n.6, p.740-759, nov./dec. 2006.

KELLER, K. L. Strategic brand management: building, measuring and managing brand equity. New Jersey: Prentice Hall, 1998. 788p.

KELLER, K. L.; MACHADO, M. Gestão estratégica de marcas. São Paulo: Pearson Prentice Hall, 2006.

KOTLER, P. Marketing Management: Analysis, Planning, Implementation, and Control. São Paulo: Atlas, 1994. 725p.

KRASNIKOV, A.; MISHRA, S.; OROZCO, D. Evaluating the financial impact of branding using trademarks: a framework and empirical evidence. Journal of Marketing, v.73, n.6, 154166, 2009.

LAUX, F. N.; ALMEIDA, S. O.; PEREIRA, R. C.F. Marketing de gerações: Construção e teste de escala para avaliação da marca de refrigerante coca-cola por jovens na fase de transição entre as gerações x e y. In: XXIX ENANPAD, Brasília, 2005. Anais... Brasília: ANPAD, 2005.

LEÃO, A. L. M. "Valor de Marca" para Quem? - Rumo a uma Teoria da Significação das Marcas pelos Consumidores. In: XXXI ENANPAD, Rio de Janeiro, 2007. Anais... Rio de Janeiro: ANPAD, 2007.

LEÃO, A. L. M. S.; SOUZA NETO, A. F.; MELLO, S. C. B. Compreendendo os Valores das Marcas: Aplicação da Lista de Valores em Diferentes Indústrias. RAC - Revista de Administração Contemporânea, v.11, p.27-48, mai./jun. 2007.

LEÃO, A. L. M. S.; SOUZA NETO, A. F. Descobrindo os Valores das Marcas: Aplicação da Lista de Valores (LOV) em Diferentes Setores. In: XXVII ENANPAD, Atibáia, 2003. Anais... Atibaia: ANPAD, 2003.

LOURO, M. J. S. Modelos de avaliação de marca. RAE - Revista de Administração de Empresas, São Paulo. v.40, n.2, p.26-37, abr./jun. 2000.

MACEDO, M. A. S.; OLIVEIRA, M. A. Avaliação Estratégica de Ativos Intangíveis: uma Proposta de Modelagem DEA Aplicada ao Valor da Marca e Performance Organizacional de 
O valor da marca: conceitos, abordagens e estudos no Brasil

Bancos no Mercado Brasileiro. In: II ENCONTRO DE ESTUDOS DE ESTRATÉGIA (3Es), Rio de Janeiro, 2005. Anais... ANPAD: Rio de Janeiro, 2005.

MADDEN, T. J.; FEHLE, F.; FOURNIER, S. Brands Matter: An Empirical Demonstration of the Creation of Shareholder Value Through Brands. Journal of the Academy of Marketing Science, v.34, n.2, p.224-235, Spring 2006.

MALHOTRA, N. K. Pesquisa de marketing: uma orientação aplicada. $3^{\circ}$ ed. Porto Alegre: Bookman, 2001.

MARTINS, J. R. Brand Equity como Fluxo Financeiro. Disponível em: <http://www. globalbrands.com.br/artigos.asp?id=64>. Acesso em: dez. 2007.

MELLO, S. C. B.de, LEÃO, André M.; SOUZA NETO, A. F. de S. N. Que valores estão na moda? Achados muito além do efêmero. RAM - Revista de Administração Mackenzie, a. 4, n.2, 2003.

MIZIK, N.; JACOBSON, R. Valuing branded businesses. Journal of Marketing, v.73, n.6, 137-153, 2009.

MONTANGES, C. P.; RIEL, A. Brand Equity and Shareholder Value. European Management Journal, v. 21, n. 4, p. 521-527, 2003.

MORGAN, R. P. A consumer-orientated framework of brand equity and loyalty. International Journal of Market Research, v. 42, n. 1, p. 65-78, 2000.

MURAD, F. B., TORRES, D. F.. Marcas próprias e valor da marca: o estudo de caso da marca própria Carrefour. XXXII ENANPAD, São Paulo, 2008. Anais... Rio de Janeiro: ANPAD, 2008.

NETO, A. V.; LUCE, F. B. Mensuração de brand equity baseado no consumidor: avaliação de escala multidimensional. In: II ENCONTRO DE MARKETING DA ANPAD, Rio de Janeiro, 2006. Anais... ANPAD: Rio de Janeiro, 2006.

OLIVEIRA, D. F. Relações entre a Reputação e o Valor da Marca no Setor Automotivo. In: XXXI ENANPAD, Rio de Janeiro, 2007. Anais... Rio de Janeiro: ANPAD, 2007.

OLIVEIRA, M. O. R. de; LUCE, F. B. O valor da marca e o valor ao acionista em empresas brasileiras. XXXIII ENANPAD, São Paulo, 2009. Anais... São Paulo: ANPAD, 2009. 
Marta Olivia Rovedder de Oliveira \& Fernando Bins Luce

OLIVEIRA, M. O. R. de. Valor da marca: conceitos, abordagens e estado da arte no Brasil. In: III EMA, 2008, Curitiba. Anais... ANPAD: Curitiba, 2008.

PAIXÃO, R. B.; BRUNI, A. L.; ADEIRA, R. Nem Tudo Que Reluz É Ouro: um Estudo da Interferência da Força da Marca na Formação dos Preços com o Uso de Testes de Correlação e Análise de Conglomerados. In: XXX ENANPAD, 2006, Salvador. Anais... Salvador: ANPAD, 2006.

PEREZ, M. M.; FAMA; R. Características Estratégicas dos Ativos Intangíveis e o Desempenho Econômico da Empresa. In: XXVIII ENANPAD, 2004, Curitiba. Anais... ANPAD: Curitiba, 2004.

PEREIRA, R. F. C. Marketing de gerações: Construção e teste de escala para avaliação da marca de refrigerante coca-cola por jovens na fase de transição entre as gerações x e y. REAd - Revista Eletrônica de Administração, v.12, n.4, jul./ago. 2006.

RAGGIO, R. D.; LEONE, R. P.. The Theoretical Separation of Brand Equity and Brand Value: managerial implications for strategic planning. Journal of Brand Management, v.14, p.380-395, Mar. 2007.

REGO, L. L.; BILLET, M. T.; MORGAN, Neil A. Consumer-based brand equity and firm risk. Journal of Marketing, v.73, n.6, 47-60, 2009.

RUST, R. T., LEMON, K. N., ZEITHAML, V. A. Return on Marketing: Using Valor do cliente to Focus Marketing Strategy. Journal of Marketing, v. 68, p. 109-27, Jan. 2004a.

RUST, R. T. et al. Measuring Marketing Productivity: current knowledge and future directions. Journal of Marketing, v.86, p.76-89, Oct. 2004b.

SANTANA, S. Arruda. Comunicação Integrada de Marketing em Empresas de Tecnologia da Informação: Realidade ou Utopia no Estabelecimento do Valor de Marca? In: XXVIII ENANPAD, 2004, Curitiba. Anais... ANPAD: Curitiba, 2004.

SHANKAR, V.; AZAR, P.; FULLER, M. Bran*eqt: a model and simulator for estimating, tracking, and managing multicategory brand equity. MSI Trustees Meeting, San Francisco, 2007. 
O valor da marca: conceitos, abordagens e estudos no Brasil

SILVA, R. R. da, AMSTALDEN, R. R., SILVA, T. P. F. Influências do valor da marca da Petrobras BR: um estudo com consumidores do segmento de combustíveis. In: III EMA, 2008, Curitiba. Anais... ANPAD: Curitiba, 2008.

SIMON, C.; SULLIVAN, M. W. The measurement and determinants of brand equity: a financial approach. Marketing Science, v.12, n.1, p.28-52, Winter 1993.

SRIVASTAVA, R. K., SHERVANI, T. A.; FAHEY, L. Market-Based Assets and Shareholder Value: A Framework for Analysis. Journal of Marketing, v. 62, p. 2-18, Jan. 1998.

STRINGHETTI, L. S. S. Criação de valor de marca - estudo de caso no banco do Brasil. Dissertação (Mestrado em Engenharia da Produção) - Programa de Pós-Graduação em Engenharia de Produção da UFSC, Florianópolis, 2001.

TARSITANO, P. R.; NAVACINSK, S. D. G. Marca: patrimônio das empresas e diferencial dos produtos. Comunicação \& Sociedade. São Bernardo do Campo: PósCom-Umesp, n.41, p.55-72, 1o. sem. 2004.

THORSTEN; H.; HOUSTON, M. B.; HEITJANS, T. Conceptualizing and measuring the monetary value of brand extensions: the case of motion pictures. Journal of Marketing, v.73, n.6, 167-183, 2009.

TRINTA, J. L. Metodologias Financeiras para Avaliação de Marcas. $3^{\circ}$ Congresso de Comunicação e Marketing - CENPRO. Fundação Getúlio Vargas. 2006.

VARGAS NETO, A. Mensuração de brand equity baseada no consumidor: avaliação de escala multidimensional. Dissertação (Mestrado em Administração) - Escola de Administração da UFRGS, Porto Alegre, 2003.

VILLANUEVA, J.; HANSSENS, D. M. Customer Equity: Measurement, Management and Research Opportunities. Foundations and Trends in Marketing. v.1, n.1, p.1-95, 2007.

WOOD, L. Brands and brand equity: definition and management. Management Decision, v.38, n.9, p.662-669, 2000.

WOODRUFF, R. B.; GARDIAL, S. F. Know your customer: new approaches to understanding customer value and satisfaction. Cambridge, MA: Blackwell Publishers, 1996. 
YEUNG, M.; RAMASAMY, B. Brand value and firm performance nexus: Further empirical evidence. Journal of Brand Management, v.28, n.2, p.195-211, Jul. 2007.

YOO, B.; DONTHU, N.; LEE, Sungho. An examination of selected marketing mix elements and brand equity. Journal of Academy of Marketing Science, Greenvale, v. 28, n. 2, p. $195-$ $211,2000$.

ZEITHAML, V. Consumer perceptions of price, quality, and value - a means-end model and synthesis of evidence. Journal of Marketing, v. 52, p. 2-22, July 2002.

\title{
RESUMO
}

O valor da marca é um importante construto a ser estudado porque é associado a benefícioschave tanto para os consumidores quanto para as empresas, de forma que existe um crescente reconhecimento de que as marcas são recursos capazes de melhorar o valor ao acionista. $\mathrm{O}$ presente estudo visa verificar os estudos relativos ao valor da marca realizados no Brasil. Para tanto, primeiramente revisa conceitos e construtos existentes. Após, aponta alguns modelos de mensuração e, por fim, realiza um levantamento, dentre algumas das principais publicações brasileiras de administração, sobre os trabalhos realizados atinentes a esse tema. $\mathrm{O}$ levantamento dos estudos demonstrou que, nos últimos anos (2007 e principalmente 2006), ocorreu um crescimento dessas pesquisas, mas ainda há um amplo caminho para esses estudos no Brasil. Muitos estudos são de caráter teórico-conceitual, existindo espaço para avanços em pesquisas de caráter empírico. Crê-se que ainda haja espaço para pesquisas que relacionem o desempenho da marca ao desempenho empresarial, seja lucratividade ou valor ao acionista. Também existe uma carência de estudos que observem concomitantemente a perspectiva de valor dos consumidores e das empresas. Dentre as contribuições que essa pesquisa buscou oferecer destacam-se, além dos conceitos, modelos e estudos levantados, a indicação de futuras pesquisas no Brasil.

Palavras-chave: valor da marca; conceitos; abordagens de mensuração; estudos no Brasil.

\section{BRAND EQUITY: CONCEPTS, APPROACHES AND STUDIES IN BRAZIL}

\begin{abstract}
Brand equity is an important construct to be studied because it is associated to key benefits for both customers and companies, as it is increasingly acknowledged that brands are resources able to improve the stockholder value. This study seeks to review the studies related to brand equity performed in Brazil. As such, it first reviews existing concepts and constructs. Then it points out some measuring models, and finally performs a survey of the papers published on this theme in the main Brazilian administration publications. The survey of the studies has shown that, in the last few years (2007 and specially 2006), there has been an increase of these researches, but there is still a long way for these studies in Brazil. Many studies are of theoretical-conceptual nature, and there is room for more empirical research advance. It is believed that there is room for research that relates brand performance to company performance, be it profitability or stockholder value. There is also a shortage of studies which take in consideration both the customers' and the companies' perspective. Among the contributions this research has tried to make, one can highlight, besides the concepts, models and studies surveyed, the recommendation of future research in Brazil.
\end{abstract}

Keywords: brand equity; concepts; measuring approaches; studies in Brazil. 